\title{
Endogenous Price Leadership with Asymmetric Costs: Experimental Evidence
}

\author{
January 21, 2019
}

\begin{abstract}
This paper presents experimental evidence on the action commitment game with costasymmetric firms in a differentiated products Bertrand duopoly. Unlike its quantity-setting counterpart, the risk-dominant leader-follower equilibrium Pareto-dominates the simultaneousmove equilibrium. This equilibrium also minimizes payoff differences between firms. Hence, one would expect the model to accurately capture behavior. The evidence partially supports the theory: low-cost firms price in period one more often than high-cost firms, and depending on the treatment, between $40 \%$ and $57 \%$ of all observations conform to equilibrium play. However, the modal timing outcome involved both firms delaying their pricing decision. This timing outcome is characterized by Nash play and some collusion. The high frequency of delaying decisions could be due to a desire to reduce strategic uncertainty.
\end{abstract}

Keywords: commitment, endogenous timing, Bertrand, price differentiation, experiment JEL classification numbers: C72, C92, D43 


\section{Introduction}

The action commitment game by Hamilton and Slutsky (1990) is one of the seminal contributions to the literature on games of endogenous timing. It describes a two period duopoly, in which firms choose whether to produce/price in either period one or wait until period two. If a firm chooses period one, it will not know its counterpart's action. Waiting, in contrast, allows it to know the choice the other firm made. This model is important to the industrial organization literature because it provides a theoretical basis for the emergence of market leaders. While it is known that the Stackelberg equilibrium is more efficient than the Cournot equilibrium (Daughety, 1990), prior to the endogenous timing literature it was not obvious why and how a market leader would emerge.

Following Hamilton and Slutsky's original work, there has been an increasing interest in studying the conditions for the endogenous emergence of market leadership (e.g. Normann, 2002; van Damme and Hurkens, 2004). However, the experimental evidence to date has not supported the theory. Huck, Müller and Normann (2002) tested Hamilton and Slutsky's (1990) model and they found that behavior was consistent with simultaneous-move Cournot play. The data from their experiment showed that only roughly $5 \%$ of observations were consistent with the predicted equilibria. Rather, most observations recorded Cournot play, collusion or punishment by followers of Stackelberg leader quantities. The authors justified this behavior on coordination problems due to firms being symmetric.

In order to tackle the issue of coordination problems stemming from the symmetric nature of the original action commitment game, Fonseca, Huck and Normann (2005) conducted a test of the asymmetric version of the action commitment game proposed by van Damme and Hurkens (1999). Their data again showed little evidence in favor of the emergence of Stackelberg leaders, as most subjects committed to period one production and Cournot outputs were modal. ${ }^{1}$ SantosPinto (2008) argued that such behavior could be explained by players being averse to inequality in payoffs. He showed that if players exhibit social preferences of the form proposed by Fehr and Schmidt (1999), there may be multiple simultaneous-move equilibria in period one, as well as punitive behavior by second-movers via high quantities as a best-response to the Stackelberg output in period one.

\footnotetext{
${ }^{1}$ Furthermore, other experimental studies of other endogenous timing models have also found little evidence supporting their predictions. Müller (2006) investigated the timing game proposed by Saloner (1987), while Fonseca, Müller and Normann (2006) studied the extended game with observable delay developed by Hamilton and Slutsky (1990). Nosenzo and Sefton (2011) look at endogenous timing in a public good game.
} 
This evidence makes a strong case for testing the action commitment game with pricesetting firms and asymmetric costs. Unlike the quantity-setting game, there is a strategic incentive to move second in the price-setting game. However, since being a first-mover is always most profitable than playing a simultaneous-move game, both sequential-move equilibria Pareto-dominate the simultaneous-move equilibrium. Furthermore, asymmetry in costs should help firms coordinate on who moves first via risk dominance arguments (van Damme and Hurkens, 2004). Finally, inequality-averse individuals should prefer the risk-dominant equilibrium, since it minimizes payoff differences between the two firms.

We find that low-cost firms commit to period one pricing more often than high-cost firms. However, a large proportion of firms in the experiment delay their pricing decisions to the second period. This means the modal timing outcome is where both firms play a simultaneous-move game in period two. Behavior in this subgame is characterized by prices close to the Nash equilibrium of the static game, as well as collusive prices in some markets. Since average prices posted by firms who commit to period one are not very different to the static game Nash equilibrium, the resulting small differences in profits make delaying an attractive action, particularly since delaying may reduce strategic uncertainty.

\section{The Model}

We consider a differentiated product price setting duopoly, where demand is given by

$$
D_{i}\left(p_{i}, p_{j}\right)=\max \left\{20-p_{i}+0.5 p_{j}, 0\right\}, i \neq j
$$

with firms' cost functions given by

$$
\begin{aligned}
& C_{1}\left(q_{1}\right)=2 q_{1}, \\
& C_{2}\left(q_{2}\right)=8 q_{2} .
\end{aligned}
$$

The profit of firm $i$ is given by $\pi_{i}\left(p_{i}, p_{j}\right)=\left(p_{i}-c_{i}\right)\left(D_{i}\left(p_{i}, p_{j}\right)\right)$. The (unique) best reply of firm $i$ to a price $p_{j}$ is:

$$
b_{i}\left(p_{j}\right)=\frac{20+c_{i}}{2}+\frac{1}{4} p_{j}
$$

Firm $i$ 's leader price is the unique maximizer of the function $p_{i} \rightarrow \pi\left(p_{i}, b_{j}\left(p_{i}\right)\right)$ is $p_{i}^{L}$. Denote $p_{i}^{F}$ as firm $i$ 's follower price, $p_{i}^{F}=b_{j}\left(p_{i}^{L}\right)$. Let $L_{i}=\pi_{i}\left(p_{i}^{L}, p_{j}^{F}\right)$ and $F_{i}=\pi_{i}\left(p_{i}^{F}, p_{j}^{L}\right)$ denote leader and follower profits, respectively. Let $p_{i}^{N}$ be the Bertrand-Nash equilibrium price of the one-period game and $N_{i}=\pi_{i}\left(p_{i}^{N}, p_{j}^{N}\right)$ the corresponding profit for firm $i$. 
Firms prefer being a follower to being a leader, and prefer being a leader to playing a simultaneous-move game: $F_{i}>L_{i}>N_{i}$. Firms play the Action Commitment game of Hamilton and Slutsky (1990), where they must select a price in either of two periods. If firm $i$ sets a price in period one, it will not be informed of the actions of its counterpart. If it waits, which we denote by $w_{i}$, it will know what the choice the other firm made in period one. Equation 5 describes payoffs for firm $i$ if both firms price in the first period; equation 6 defines payoffs for firm $i$ if it commits to period one and firm $j$ delays; equation 7 describes payoffs for firm $i$ if it delays its pricing decision to the second period and firm $j$ prices in period one. Finally, equation 8 defines payoffs to firm $i$ if both firms delay their pricing decision to period two.

$$
\begin{array}{r}
\pi_{i}\left(p_{i}, p_{j}\right)=\left(p_{i}-c_{i}\right)\left(20-p_{i}+0.5 p_{j}\right) \\
\pi_{i}\left(p_{i}, w_{j}\right)=\left(p_{i}-c_{i}\right)\left(20-p_{i}+0.5\left(\frac{20+c_{i}}{2}+\frac{1}{4} p_{j}\right)\right) \\
\pi_{i}\left(w_{i}, p_{j}\right)=\left(\frac{20+c_{i}}{2}+\frac{1}{4} p_{j}\right)^{2} \\
\pi_{i}\left(w_{i}, w_{j}\right)=N_{i}
\end{array}
$$

This game has three pure-strategy equilibria. ${ }^{2}$ Firms either both select prices $p_{i}^{N}$ in the first period, or one of them chooses a price $p_{i}^{L}$ in the first period while the other sets a price $p_{i}^{F}$ in the second period. In the game considered in this experiment with a discrete and finite strategy space, the equilibrium where the efficient firm leads risk-dominates the equilibrium where the inefficient firm leads. The relevant proofs are included in the Appendix.

If the game is finitely repeated, then there are multiple equilibrium paths: any sequence of stage-game equilibria is an equilibrium of the repeated game. In this case, it is difficult to predict what equilibrium path should be played. Any equilibrium path in which players play the simultaneous-move equilibrium game at least once is Pareto-dominated by any equilibrium path where players never play the Bertrand-Nash equilibrium. However, there is no obvious way to select amongst the multiple equilibrium paths remaining. Theoretically, there is no possibility of collusive equilibria in this environment using standard backward-induction arguments. However, there is substantial evidence that cooperation is possible even in finitely repeated games. Embrey et al. (2018) provide a meta-analysis of data from the Prisoners' Dilemma. This suggests collusive behavior may be possible in the experimental environment.

\footnotetext{
${ }^{2}$ Following van Damme and Hurkens (2004), we only consider pure-strategy equilibria.
} 


\begin{tabular}{|c|c|c|}
\hline \multirow{3}{*}{$\begin{array}{c}\text { End Timing } \\
\text { Control }\end{array}$} & RANDOM & FIXED \\
\hline & 6 & 6 \\
\hline & 6 & 6 \\
\hline
\end{tabular}

Table 1: Experimental design. Numbers in cells are the number of independent observations.

\section{The Experiment}

\subsection{Experimental Design}

The experiment implements the endogenous timing model laid out in Section 2. The control treatment consists of the simultaneous-move game. In addition, we conducted sessions where subjects' matching was random (RANDOM), as well as sessions where subjects were matched with the same partner for the whole session (FIXED). The random matching treatment best approximates the one-shot nature of the game. However, since at the heart of this experiment lies a coordination problem, the fixed matching treatment provides the best environment for subjects to be able to coordinate on the efficient equilibrium, as it reduces the strategic uncertainty subjects face in the experiment. Also, real world firm interaction is better characterized by repeated interaction rather than random matching. Table 1 outlines the experimental design. There were six independent observations in each condition - ten-subject sessions in the case of RANDOM and pairs in the case of FIXED.

\subsection{Hypotheses}

We now briefly set out the hypotheses underpinning the experiment. As discussed earlier, the risk-dominant equilibrium is the sequential-move equilibrium in which the low-cost firm prices in period one. This is also the equilibrium which maximizes total profits, and minimizes payoff differences. This should be reflected in subjects' timing choices, irrespective of the matching protocol implemented in the experiment.

Hypothesis 1: Low-cost firms will choose to price in period one more often than high-cost firms in both RANDOM and FIXED.

We now turn to pricing behavior. Theory predicts that conditional on any given subgame (that is, choosing to price in period one, follower in a sequential-move subgame, or playing a simultaneous-move game in period two) low-cost firms will select lower prices than high-cost firms. 
Hypothesis 2: Conditional on a chosen subgame, low-cost firms will pick lower prices than highcost firms in both FIXED and RANDOM.

We are also interested in understanding pricing behavior conditional on the matching protocol. Given that the game is finitely-repeated, there is no theoretical basis for expecting differences in pricing behavior. However, there is ample evidence that fixed matching protocols give rise to collusive behavior even in finitely repeated markets (Huck, Müller, Normann, 2001; Kübler, Müller, 2002; Embrey et al., 2018). It is therefore possible that similar patterns may emerge in our game, especially given firms set prices. Since prices are strategic complements, any collusive deviation from a Nash equilibrium price will be matched by a similar deviation. ${ }^{3}$

Hypothesis 3: Conditional on a chosen subgame, average prices will be higher in FIXED than in RANDOM.

\subsection{Procedures}

In all treatments, subjects were sorted into roles (high cost or low cost) in the beginning of the session and retained those roles throughout the experiment. Each subject sat in an individual computer booth. Verbal communication between subjects during the sessions was not allowed. Each session began by the experimenter reading the instruction set aloud to establish common knowledge of the experimental conditions. After that, there was a short period for subjects to query the experimenter, followed by a short quiz, whose purpose was to ensure everyone understood the mechanics of the experiment before the experiment itself began. Each session had 30 rounds, and lasted on average one hour.

The instruction sets (available in the Appendix) informed participants that they were taking the role of a firm that was in a market with another firm. Subjects taking part in the main treatment read that in each round of the experiment they could choose to set their price in the first period or that they could wait until the second period to do so. Choosing period one to set their price meant they would not know what their counterpart had chosen, but if they chose to wait they would be informed of what he or she had done before making their decision. To assist them in their decisions they had a payoff matrix with information on profits for both players conditional on both players' price choices. All decisions were done through a computer terminal using Z-Tree

\footnotetext{
${ }^{3}$ In contrast, in quantity setting games, the best response to a collusive deviation from equilibrium output is to do the opposite.
} 


\begin{tabular}{ccc}
\hline \hline & RANDOM & FIXED \\
\hline Low-cost & $30 \%$ & $52 \%$ \\
High-cost & $16 \%$ & $13 \%$ \\
\hline \hline
\end{tabular}

Table 2: Frequency of period one pricing decisions

(Fischbacher, 2007), and all feedback was also given on screen, both after each decision was made (i.e. the choice of the other firm if a subject had chosen to wait) and after each round was over.

The experimental sessions for the FIXED treatment took place in the Experimental Economics Laboratory in the Economics Department at Royal Holloway, University of London, in the Fall of 2004 and the sessions for the RANDOM treatment in the FEELE lab at the University of Exeter in the Fall of 2009. The subject pool in both sites consisted of undergraduate students from a variety of backgrounds. Ten to twelve subjects participated in each session and no subject participated in more than one session. We conducted a total of 14 sessions with 144 participants in total. Subject payments consisted of the sum of all periods' payoffs; average payment was £17 $(\$ 31.60)$.

\section{Experimental Results}

In our analysis of the data, an independent observation in the FIXED treatment is the average behavior across 30 periods by a pair of subjects. In the RANDOM treatment, an independent observation is the average behavior across 30 periods by all participants in that session. When presenting and discussing results, we will denote ' $t=1$ ' and ' $t=2$ ' as the first and second pricing periods in a given round. When reporting significance levels on non-parametric tests, we always refer to two-sided tests.

\subsection{Timing Choices and Timing Outcomes}

We begin by looking at timing decisions. Table 2 displays the frequency with which low cost and high cost firms picked prices in period one. It is notable that low cost firms always pick their prices in period one more often than high cost firms in both RANDOM $(p=0.055)$ and Fixed $(p=0.020)$ treatments. ${ }^{4}$ However, the frequency with which low-cost firms price in period one is quite far

\footnotetext{
${ }^{4}$ In rounds 1-10, the differences between roles are significant at the $5 \%$ in both treatments; in rounds 11-20, the difference between roles is only significant for RANDOM at the $10 \%$ level; in rounds $21-30$, there are no significant
} 

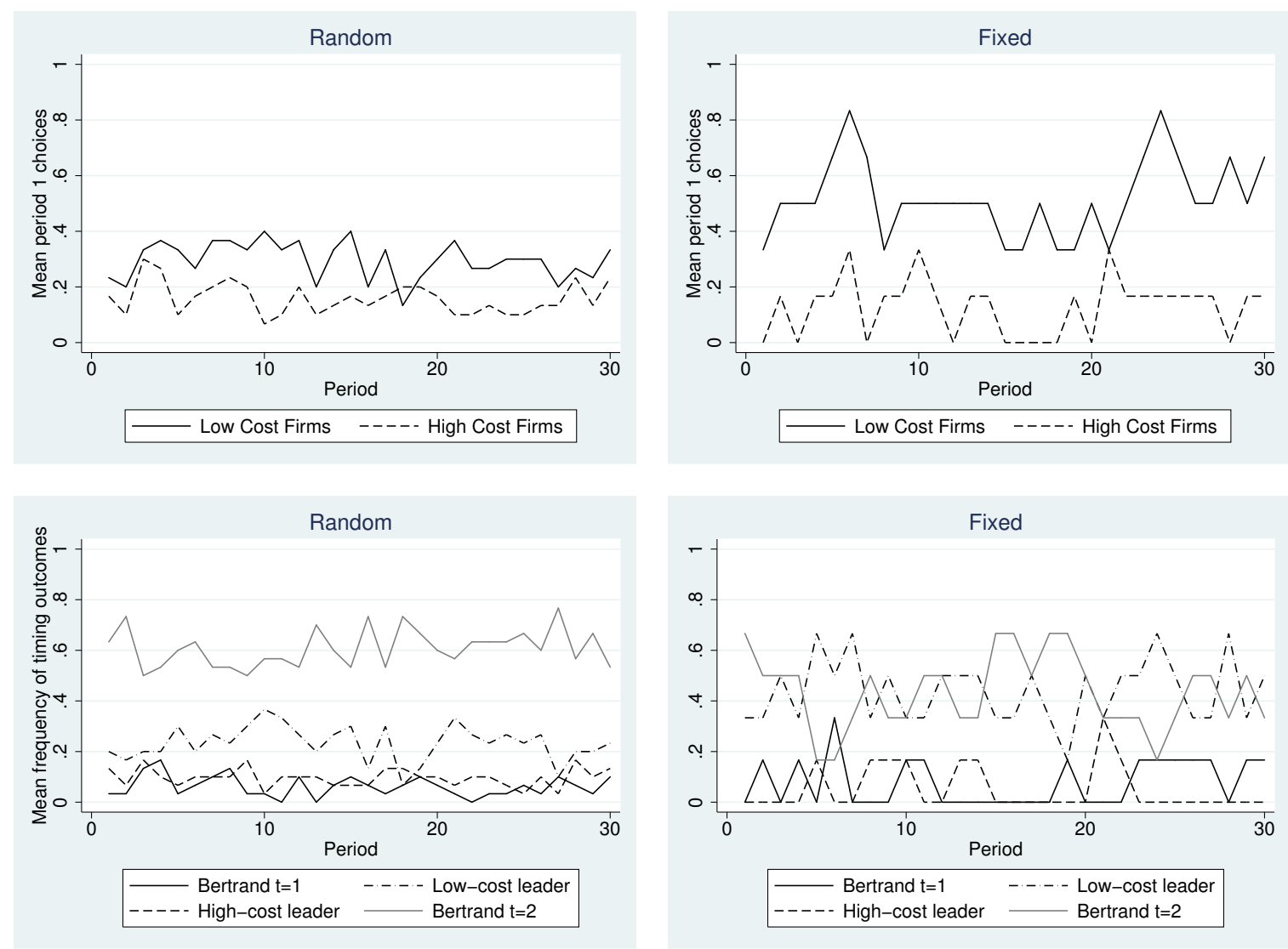

Figure 1: Time series of average timing decisions by firm type (top) and timing outcomes (bottom) in RANDOM (left) and FIXED (right).

from $100 \%$. Focusing now on treatment differences, the low-cost firms in FIXED price in period one more often than their counterparts in RANDOM. Finally, looking at the evolution of timing choices over the course of the experiment, the top row of Figure 1 shows that the frequency of period one choices is quite stable throughout the session, with the exception of the high-cost firms in FIXED, whose frequency of period one choices dips in the second third of the experiment, only to rise in the final third. How do timing decisions by individuals translate into timing outcomes in the game? Table 3 summarizes the frequency with which each of the four timing outcomes occurred in both treatments. In RANDOM, $23 \%$ of observations are consistent with the low-cost leader equilibrium, while $10 \%$ of observations record the high-cost firm leading — a significant difference (McNemar's differences between roles in either treatment; across all rounds, both treatments show significant differences between roles (5\% level for RANDOM and 10\% level for FIXED). All comparisons tested using Wilcoxon sign-rank test for paired samples. 


$$
\begin{aligned}
& \text { High-cost High-cost }
\end{aligned}
$$

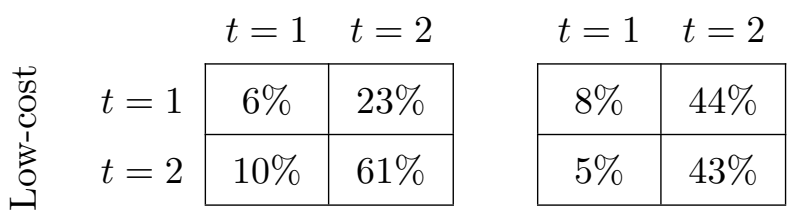

$$
\begin{aligned}
& \text { RANDOM FIXED }
\end{aligned}
$$

Table 3: Relative frequency of timing outcomes - all periods

test, $p<0.01)$. However, the majority of observations have both firms delaying their pricing decision to period two. In FIXED, there are two modal timing outcomes: the first is where the low-cost firm leads with $44 \%$ of observations, which is significantly more frequent than the outcome in which the high-cost firm leads (McNemar's test, $p<0.01$ ). The second most observed timing outcome with $43 \%$ of observations is where both firms delay their timing decisions.

The bottom row of Figure 1 displays the evolution of the relative frequencies of the four timing outcomes over the course of the experiment. Bertrand play in the second period, and the low-cost leader equilibrium are consistently the two most frequent timing outcomes in the FIXED treatment, while period-two Bertrand is the modal outcome throughout in the RANDOM treatment. ${ }^{5}$ The following summarizes our finding from the timing analysis.

Finding 1: Low-cost firms price in period one more often than high-cost firms in both treatments. The simultaneous-move pricing subgame in period two is the modal outcome in RANDOM. The riskdominant equilibrium and the simultaneous-move subgame in period two are the modal outcomes in FIXED.

\subsection{Pricing decisions}

We now turn to the analysis of pricing decisions by firms. Theory predicts low-cost firms will charge a lower price than high-cost firms in equilibrium for a given timing decision. Recall that in equilibrium, a low-cost price will set a lower price if it chooses to price in period 1 than a high-cost firm that prices in period 1. Likewise, a low-cost follower will set a lower price than a high-cost follower. In addition, in a Bertrand equilibrium, a low-cost firm will set a lower price than a high-cost firm. In short, $p_{1}^{L}<p_{2}^{L}, p_{1}^{F}<p_{2}^{F}$ and $p_{1}^{N}<p_{2}^{N}$.

\footnotetext{
${ }^{5}$ There were no significant differences in the average proportion of each timing outcome over the two halves of the experiment in either FIXED or RANDOM using Wilcoxon signed rank test for paired samples.
} 
Table 4 reports the average prices chosen by firms in the main treatment, conditional on having chosen period one, being a follower or having played a simultaneous-move game in period two. As predicted, low-cost firms charge significantly lower prices than high-cost firms for a given subgame. This is the case for both RANDOM and FiXED treatments. ${ }^{6}$

Finding 2: Low-cost firms always set lower prices than high-cost firms in all subgames in both RANDOM and FIXED treatments.

We now turn to the comparison of pricing behavior between RANDOM and FIXED. We find no statistically significant difference in average prices in any pairwise comparison between the two matching treatments. ${ }^{7}$ This is our next finding.

Finding 3: We find no significant difference in average prices conditional on role and/or subgame between RANDOM and FIXED treatments.

Looking at average pricing behavior naturally ignores the heterogeneity in behavior in each of the timing outcomes. Table 5 displays the frequency with which low-cost firms priced in $t=1$, and the average price posted by high-cost firms when in the role of followers. In RANDOM, the modal price posted by low-cost firms in $t=1$ is the Bertrand-Nash equilibrium price of the oneperiod game, 16; in FIXED, the modal price is 17 . Only $4 \%$ of observations in RANDOM and $1 \%$ in FIXED record the predicted price of 15. In contrast, the behavior of high-cost firms when in the role of followers is rather close to prediction for the large majority of prices in both treatments.

Table 6 displays the same information with roles reversed: we now look at the distribution of prices posted in $t=1$ by high-cost firms and the average price posted by low-cost firms when in the role of followers. Again, most observations in both treatments record pricing behavior in $t=1$ which is closer to the one-period Bertrand Nash equilibrium $(p=17)$ than that predicted by the two-period model $(p=20)$. However, in RANDOM, the latter price is the second most observed price with $23 \%(33 / 143)$ of observations. The average price posted by low-cost firms is very close to the predicted best reply.

\footnotetext{
${ }^{6}$ All comparisons, Wilcoxon signed-rank test for paired samples. RANDOM: $p_{1}^{t=1}=p_{2}^{t=1}, p=0.046 ; p_{1}^{\text {Follower }}<$ $p_{2}^{\text {Follower }}, p=0.046 ; p_{1}^{\text {Bertrand }, t=2}=p_{2}^{\text {Bertrand }, t=2}, p=0.028$. FIXED: $p_{1}^{t=1}=p_{2}^{t=1}, p=0.068 ; p_{1}^{\text {Follower }}<p_{2}^{\text {Follower }}$, $p=0.1088 ; p_{1}^{\text {Bertrand }, t=2}=p_{2}^{\text {Bertrand }, t=2}, p=0.028$. Note however that in the first two comparisons, data was unavailable for some high-cost firms, making the number of pairs smaller than 6 .

${ }^{7}$ Low cost firms, $t=1: z=1.444, p=0.149$; Follower in $t=2: z=0.258, p=0.796$; Bertrand in $t=2$ : $z=0.320, p=0.749$. High cost firms, $t=1: z=0.426, p=0.670$; Follower in $t=2: z=-0.241, p=0.810$; Bertrand
} 


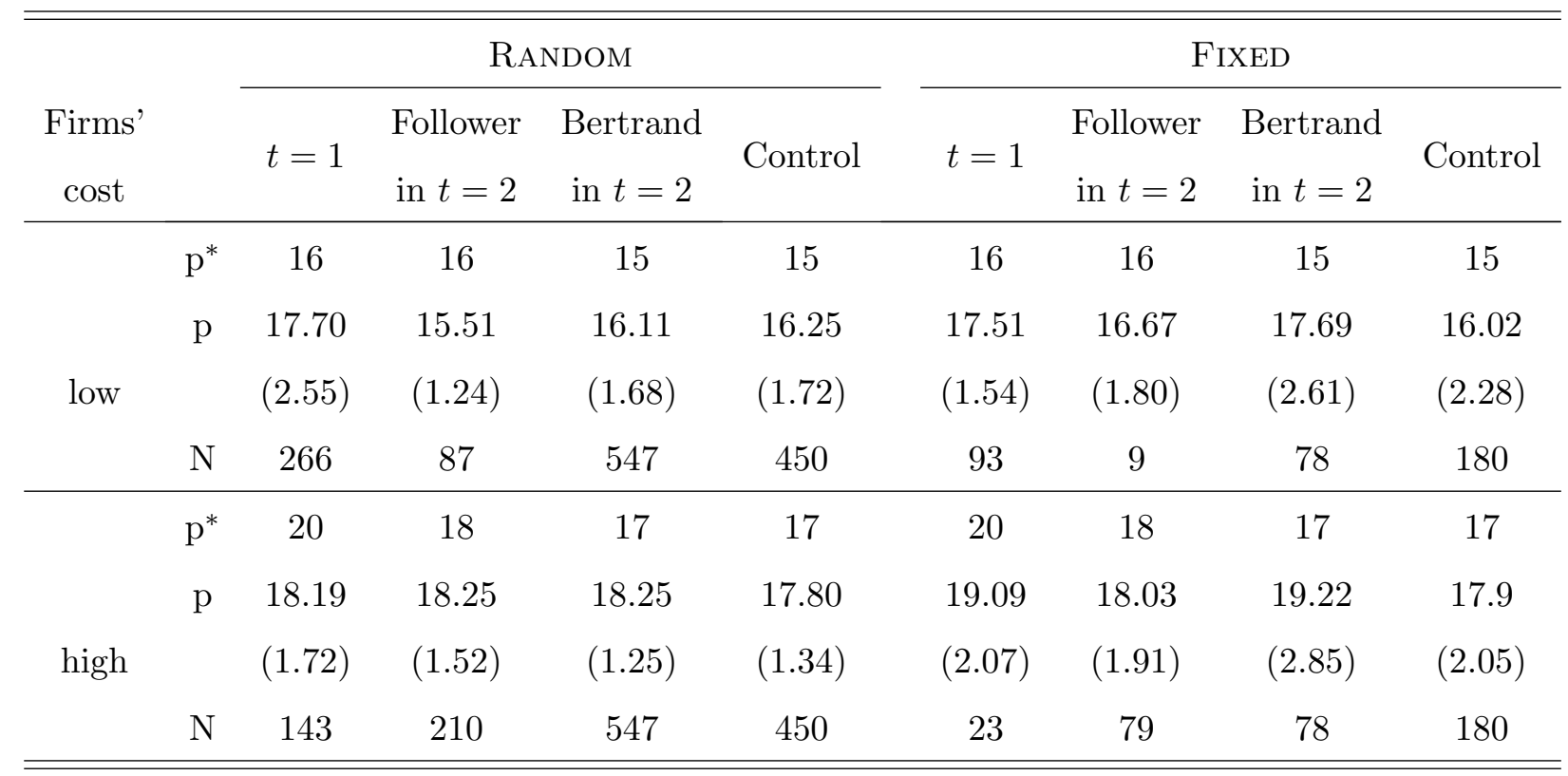

Standard deviations in parenthesis

Table 4: Average prices conditional on subgame

\begin{tabular}{ccccccccccc}
\hline \hline RANDOM & & & & & & & & & & \\
$p_{t=1}$ & 14 & 15 & 16 & 17 & 18 & 19 & 20 & 21 & 22 & 23 \\
$\mathrm{~N}$ & 12 & 10 & 103 & 35 & 35 & 20 & 6 & 8 & 2 & 35 \\
\hline$B R\left(p_{t=1}\right)$ & 17 & 17 & 18 & 18 & 18 & 19 & 19 & 19 & 20 & 20 \\
& 18.80 & 17.44 & 17.89 & 17.91 & 17.91 & 18.94 & 17.5 & 19.4 & 20 & 20 \\
$p_{t=2}$ & $(2.90)$ & $(2.19)$ & $(0.51)$ & $(2.00)$ & $(0.73)$ & $(0.25)$ & $(1.73)$ & $(0.89)$ & - & $(2.41)$ \\
$\mathrm{N}$ & 10 & 9 & 89 & 23 & 32 & 16 & 4 & 5 & 1 & 21 \\
\hline \hline
\end{tabular}

FIXED

\begin{tabular}{ccccccccccc}
$p_{t=1}$ & 14 & 15 & 16 & 17 & 18 & 19 & 20 & 21 & 22 & 23 \\
$\mathrm{~N}$ & 0 & 1 & 23 & 42 & 2 & 11 & 8 & 6 & 0 & 0 \\
\hline$B R\left(p_{t=1}\right)$ & 17 & 17 & 18 & 18 & 18 & 19 & 19 & 19 & 20 & 20 \\
& - & 17.00 & 17.96 & 17.03 & 18 & 19.18 & 18.75 & 20.60 & - & - \\
$p_{t=2}$ & - & - & $(1.43)$ & $(1.68)$ & $(0.00)$ & $(2.40)$ & $(0.46)$ & $(2.19)$ & - & - \\
& & & & & & & & & \\
$\mathrm{N}$ & 0 & 1 & 23 & 29 & 2 & 11 & 8 & 5 & 0 & 0 \\
\hline \hline
\end{tabular}

Standard deviations in parenthesis

Table 5: Distribution of low cost firms' first period prices, best replies and average replies by high cost firms in period 2 . 


\begin{tabular}{ccccccccccc}
\hline \hline RANDOM & & & & & & & & & & \\
$p_{t=1}$ & 14 & 15 & 16 & 17 & 18 & 19 & 20 & 21 & 22 & 23 \\
$\mathrm{~N}$ & 5 & 1 & 3 & 52 & 30 & 11 & 33 & 4 & 1 & 3 \\
\hline$B R\left(p_{t=1}\right)$ & 14 & 15 & 15 & 15 & 15 & 15 & 16 & 16 & 16 & 17 \\
& 14.00 & - & 14.67 & 15.07 & 14.69 & 16.14 & 16.31 & 16.00 & 16.00 & 17.00 \\
$p_{t=2}$ & $(0.00)$ & - & $(0.58)$ & $(0.47)$ & $(0.48)$ & $(2.04)$ & $(1.38)$ & $(-)$ & $(-)$ & $(0.00)$ \\
$\mathrm{N}$ & 2 & 0 & 3 & 28 & 16 & 7 & 26 & 1 & 1 & 3 \\
\hline \hline \multirow{2}{*}{ FIXED } & & & & & & & & & & \\
$p_{t=1}$ & 14 & 15 & 16 & 17 & 18 & 19 & 20 & 21 & 22 & 23 \\
$\mathrm{~N}$ & 1 & 0 & 0 & 0 & 12 & 2 & 3 & 1 & 2 & 2 \\
\hline$B R\left(p_{t=1}\right)$ & 14 & 15 & 15 & 15 & 15 & 15 & 16 & 16 & 16 & 17 \\
& - & - & - & - & 16.33 & 15.00 & 17.00 & 16.00 & 16.00 & 21.00 \\
$p_{t=2}$ & - & - & - & - & $(1.15)$ & $(-)$ & $(-)$ & $(-)$ & $(0.00)$ & $(-)$ \\
$\mathrm{N}$ & 0 & 0 & 0 & 0 & 3 & 1 & 1 & 1 & 2 & 1 \\
\hline \hline
\end{tabular}

Standard deviations in parenthesis

Table 6: Distribution of low cost firms' first period prices, best replies and average replies by high cost firms in period 2 .

We conclude the distributional analysis of pricing behavior by looking at the subgame in which both firms delay their pricing decisions to period two - see Table 7. In this case, the two firms are playing a standard Bertrand game with differentiated products, and the Nash equilibrium is that low-cost firms set a price of 15 and high-cost firms set a price of 17 . In RANDOM, most observations record behavior quite close to prediction. In FIXED the same is true, but the modal prices for low-cost and high-cost firms are 21 and 23, respectively. This suggests collusive behavior, since $(21,23)$ is the price pair which maximizes joint profits for the two firms. In fact, that pricing outcome occurred 22 times in this subgame in FIXED; however, one pair of subjects accounted for 21 such observations. This was in effect a successful collusive agreement, characterized by both subjects systematically setting prices in period two (25 rounds out of 30 ).

Finding 4: Prices set in the first period are closer to Nash equilibrium levels than the endogenous timing prediction. When in the role of follower, firms' average prices are close to predicted levels. in $t=2: z=-0.801, p=0.423$. All comparisons using Mann- Whitney test for independent samples. 


\begin{tabular}{|c|c|c|c|c|c|c|c|c|c|c|}
\hline \multicolumn{11}{|l|}{ RANDOM } \\
\hline & 14 & 15 & 16 & 17 & 18 & 19 & 20 & 21 & 22 & 23 \\
\hline Low Cost & 51 & 186 & 148 & 83 & 29 & 24 & 11 & 5 & 3 & 7 \\
\hline High Cost & 6 & 4 & 9 & 92 & 271 & 82 & 69 & 2 & 5 & 7 \\
\hline \multicolumn{11}{|l|}{ FIXED } \\
\hline & 14 & 15 & 16 & 17 & 18 & 19 & 20 & 21 & 22 & 23 \\
\hline Low Cost & 7 & 15 & 6 & 19 & 3 & 2 & 2 & 23 & 0 & 1 \\
\hline High Cost & 5 & 0 & 2 & 19 & 18 & 2 & 8 & 0 & 0 & 24 \\
\hline
\end{tabular}

Table 7: Distribution of prices in Bertrand $t=2$ timing outcome.

When playing a simultaneous-move game in period two, modal prices are close to Nash predictions, although there is some evidence of collusion in FIXED.

\subsection{The Determinants of Delaying Decision}

Having tested the main hypotheses, it is important to understand some patterns in the data, most notably the high proportion of outcomes in which both firms delayed their pricing decision. We start by looking at dynamics of pricing decisions. Table 8 outlines the relative frequency of period one pricing conditional on each of the four timing outcomes in the previous round using data from rounds 2-30 of the experiment. These frequencies are quite consistent over the course of experiment. ${ }^{8}$

Given the incentive structure in the experiment, it is plausible to argue that subjects would pick period one pricing in the current round if in the previous round they were playing a Bertrand game in $t=1$, or if they were the leader; otherwise, subjects ought to delay their pricing to $t=2 .{ }^{9}$ The data from Table 8 is only partially consistent with theory: while the large majority of both types of firms in the two treatments continue to delay when in the role of follower, the reverse is not the case when firms are in the role of leader (with the exception of low cost firms in FIXED). Evidence is also mixed when firms are playing a Bertrand game in $t=1$. However, it is difficult

\footnotetext{
${ }^{8}$ There is one exception. In the second half of the FIXED treatment sessions, the frequency of $t=1$ choices by high-cost firms following a round in which they played a Bertrand game in $t=1$ is 0.72 . However, this corresponds to 5 observations out of a total of 7 . Given the very small number of total cases, we do not feel this is a meaningful deviation from the overall pattern in the data.

${ }^{9}$ This could be the result of a myopic best-response dynamic, or subjects updating their beliefs about the behavior of the population they are facing.
} 


\begin{tabular}{lccccc}
\hline \hline & \multicolumn{2}{c}{ Random } & & \multicolumn{2}{c}{ Fixed } \\
& Low Cost & High Cost & & Low Cost & High Cost \\
\cline { 2 - 3 } \cline { 5 - 6 } Bertrand in $t=1$ & 0.60 & 0.60 & & 0.85 & 0.38 \\
Leader & 0.55 & 0.57 & & 0.82 & 0.56 \\
Follower & 0.23 & 0.07 & & 0.22 & 0.08 \\
Bertrand in $t=2$ & 0.18 & 0.08 & & 0.21 & 0.09 \\
\hline \hline
\end{tabular}

Table 8: Relative frequency of period one pricing choices conditional on timing outcome in previous round.

\begin{tabular}{ccccccc}
\hline \hline & \multicolumn{3}{c}{ RANDOM } & \multicolumn{3}{c}{ FIXED } \\
& $t=1$ & Follower & Bertrand $t=2$ & $t=1$ & Follower & Bertrand $t=2$ \\
\hline Low cost & 175.21 & 183.78 & 180.34 & 180.02 & 194.74 & 181.67 \\
& $(11.06)$ & $(11.38)$ & $(2.36)$ & $(11.57)$ & $(4.75)$ & $(9.25)$ \\
$\mathrm{N}$ & 6 & 6 & 6 & 6 & 3 & 6 \\
High cost & 100.36 & 104.61 & 99.12 & 105.32 & 106.31 & 100.05 \\
& $(6.78)$ & $(7.14)$ & $(3.52)$ & $(5.59)$ & $(2.67)$ & $(7.27)$ \\
$\mathrm{N}$ & 6 & 6 & 6 & 4 & 6 & 6 \\
\hline \hline
\end{tabular}

Standard deviations in parentheses based on group-level/session-level averages in FIXED/RANDOM.

Some cells in FIXED have $N<6$, due to those particular cases never occurring in some groups.

Table 9: Average profits by subgame.

to draw meaningful conclusions from that timing outcome, as it only accounts for about $6 \%$ of the data in either treatment. Importantly, most firms of both types continue to delay when playing a Bertrand game in $t=2$ in the previous round.

To understand the rationale for the persistent pricing in $t=2$, we look at average profits conditional on the subgame being played. As predicted, being a follower is nominally more profitable than pricing in $t=1$ for both types of firms, but these differences are small and only significant for high-cost firms (RANDOM: $p=0.075$; FixED: $p=0.075$, Wilcoxon signed-rank test for paired samples). Interestingly however, playing a Bertrand game in $t=2$ was also (nominally) more profitable than pricing in $t=1$, even for low cost firms - however, the only significant difference is in the RANDOM treatment $(p=0.028)$. In short, subjects are not losing significant payoff amounts by delaying their pricing decisions — sometimes even profiting from doing so. 
Finding 5: Playing the subgame where both firms delay their pricing decision to period two did not imply large payoff losses for either type of firm compared with committing to period one pricing.

\section{Conclusion}

This paper reports an experimental investigation of the model of endogenous price leadership in a two- period duopoly with asymmetric costs developed by van Damme and Hurkens (2004). The model predicts three equilibria in pure strategies: the Nash equilibrium of the static game in period one, and two sequential-moves equilibria wherein one firm prices in period one while the other waits until period two. However, the risk dominance criterion (Harsanyi and Selten, 1988) selects the equilibrium in which the low- cost firm leads.

Unlike the previous evidence on the Action Commitment game, a large proportion of the data supports the theoretical predictions. Firstly, low-cost firms priced in the first period more frequently than high-cost firms. In the treatment where firms were randomly matched every period, $40 \%$ of observations had timing outcomes consistent with equilibrium play. In the treatment where firm matching was fixed, about $57 \%$ of all observations were consistent with equilibrium play. In both treatments, out of the three equilibrium timing outcomes, the risk-dominant equilibrium was the most often observed. However, the modal timing outcome overall was the simultaneous-move game in $t=2$, which is out-of-equilibrium behavior. Behavior in this subgame is characterized by a mix of Nash equilibrium play and, in the case of one market in the fixed matching condition, collusive pricing.

While other timing outcomes are not very persistent (with the exception of low cost leader outcome in the random matching condition, delaying is persistent. Once in $t=2$ subgame, subjects are likely to continue delaying their pricing decisions. Part of the reason for this is that pricing behavior when both firms choose $t=1$ and when both firms delay is very close to the static Nash equilibrium - this is reflected in the very small payoff differentials across timing outcomes. Since playing a second mover is more profitable than being a price leader, the fact that low-cost firms gain little by pricing in $t=1$ means that delaying becomes a reasonably safe and profitable strategy. Delaying one's pricing decision to some extent also resolves part of the strategic uncertainty in the action commitment game, which makes that action even more attractive to those who may have a preference for the resolution of uncertainty (Tykocinski and Ruffle, 2003.)

While the behavior in the current setup was much more consistent with theoretical pre- 
dictions than previous research using Cournot markets, it is apparent that subjects are unwilling to overcome the strategic incentives to move first or second: when playing games of strategy substitutes, high-cost firms do not delay often enough; when playing games of strategic complements it is the low-cost firms who do not commit enough to period one. Part of the reason could lie in the quadratic nature of the profit function, which may be flat at its maximum (Harrison, 1989). This undermines the saliency of the asymmetric leader-follower equilibria, even if the stakes are high (average payments in the present experiment far exceeded hourly market wages). Further work should investigate the extent to which setups with more salient incentives can induce more equilibrium behavior.

\section{References}

[1] Daughety, A.F. 1990. Benefitial concentration. American Economic Review 80(5), 1231-1237.

[2] Embrey, M., Frechétte, G.R., Yuksel, S. 2018. Cooperation in the finitely repeated prisoner's dilemma. The Quarterly Journal of Economics 133(1), 509-551.

[3] Fehr, E., Schimdt, K. 1999. A theory of fairness, competition and cooperation. The Quarterly Journal of Economics 114, 817-868.

[4] Fischbacher, U. 2007. z-Tree - Zurich toolbox for Readymade Economic Experiments, Experimental Economics, 10, 171-178.

[5] Fonseca, M.A., Huck, S., Normann, H.-T. 2005. Playing Cournot although they shouldn't: endogenous timing in experimental duopolies with asymmetric cost. Economic Theory 25, 669677.

[6] Fonseca, M.A., Müller, W., Normann, H.-T. 2006. Endogenous timing in duopoly: Experimental evidence. International Journal of Game Theory 34, 443-456.

[7] Gal-Or, E. 1985. First mover and second mover advantages. International Economic Review 26, 649-653.

[8] Hamilton, J.H., Slutsky, S.M. 1990. Endogenous timing in duopoly games: Stackelberg or Cournot equilibria. Games and Economic Behavior 2, 29-46. 
[9] Harrison, G.W. 1989. Theory and misbehavior of first-price auctions. American Economic Review 79(4) 749-762.

[10] Harsanyi, J., Selten, R. 1988. A General Theory of Equilibrium Selection in Games, Cambridge Massachusetts: MIT Press.

[11] Holt, C.A. 1985. An experimental test of the consistent-conjecture hypothesis. American Economic Review 75, 314-325.

[12] Huck, S., Müller, W., Normann, H.-T. 2001. Stackelberg beats Cournot - on collusion and efficiency in experimental markets. Economic Journal 111, 749-765.

[13] Huck, S., Müller, W., Normann, H.-T. 2002. To commit or not to commit: endogenous timing in experimental duopoly markets. Games and Economic Behavior 38, 240-264.

[14] Kübler, D., Müller, W. 2002. Simultaneous and sequential price competition in heterogenous duopoly markets: experimental evidence. International Journal of Industrial Organization 20, $1437-1460$.

[15] Müller, W. 2006. Allowing for two production periods in the Cournot duopoly: experimental evidence. Journal of Economic Behavior and Organization 60, 100-111.

[16] Nash, J.F. 1951. Non-cooperative games. Annals of Mathematics 54, 286-295.

[17] Normann, H.-T. 2002. Endogenous timing with incomplete information and with observable delay. Games and Economic Behavior 39, 282-291.

[18] Nosenzo, D., Sefton, M. 2011. Endogenous move structure and voluntary provision of public goods. Journal of Public Economic Theory 13, 721-754.

[19] Saloner, G. 1987. Cournot duopoly with two production periods. Journal of Economic Theory $42,183-187$.

[20] Santos-Pinto, L. 2008. Making sense of the experimental evidence on endogenous timing in duopoly markets. Journal of Economic Behavior and Organization 68, 657-666.

[21] Tykocinski, O.E., Ruffle, B.J. 2003. Reasonable Reasons for Waiting. Journal of Behavioral Decision Making 16, 1-11. 
[22] van Damme, E., Hurkens, S. 1999. Endogenous Stackelberg leadership. Games and Economic Behavior 28, 105-129.

[23] van Damme, E., Hurkens, S. 2004. Endogenous price leadership. Games and Economic Behavior 47, 404-420.

\section{Appendix NOT FOR PUBLICATION}

\section{Proof}

We show here that the equilibrium where the low-cost firm leads is the risk-dominant equilibrium. Table 1 shows the reduced form game resulting from Equations $1-3^{10}$. Denote this game as $\Gamma^{1}$. The payoffs associated with the waiting action for both players are the payoffs of the equilibria of the associated subgames, following van Damme and Hurkens (2004). This game has 3 equilibria in pure strategies, the simultaneous Nash equilibrium, $(15,17)$ and the two sequential Nash equilibria, $(16, W)$ and $(W, 20)$.

In order to determine the risk-dominant equilibrium, one must use the tracing procedure developed by Harsanyi and Selten (1988). This procedure tries to capture "a process of convergent expectations [...] by which rational players will come to adopt, and to expect each other to adopt, one particular equilibrium point" (Harsanyi and Selten (1988), p. 137) as the outcome for the particular game under consideration. Since a priori, neither player will have any specific theory concerning the strategies to be used by the other player, she will express her expectations regarding the behavior of the other player by means of a subjective probability distribution, $\rho_{j}=\left(\rho_{j 1}, \ldots, \rho_{j k}\right)$, where $\rho_{j k}$ is the subjective probability that player $i$ assigns to the hypothesis that player $j$ will use pure strategy $k$. Following Harsanyi and Selten (1988), we invoke the principle of insufficient reason to assume that player $i$ will assume $\rho_{j}$ to be uniformly distributed on the action space $k=\{14,15, \ldots, 23, W\}$.

We can then construct an auxiliary game $\Gamma^{0}$, whose payoff function for player $i$ is a function of her strategy space and $\rho_{j}$, which is depicted in Table 2 . We can now proceed to construct the linear tracing procedure, which is based on a one-parameter family of auxiliary games $\Gamma^{t}$ with $0 \leq t \leq 1$. In any game $\Gamma^{t}$ every player $i$ will have the same strategy set $\mathcal{P} \cup\{W\}$ as in the original

\footnotetext{
${ }^{10}$ Because we are dealing with a duopoly with linear demand and cost with a discrete action space, multiple equilibria may arise (Holt, 1985). We therefore subtracted 1 profit unit from 14 out of the $2 \times 10 \times 10=200$ entries to ensure uniqueness of best-replies and the existence of the simultaneous-move and two sequential-move equilibria.
} 


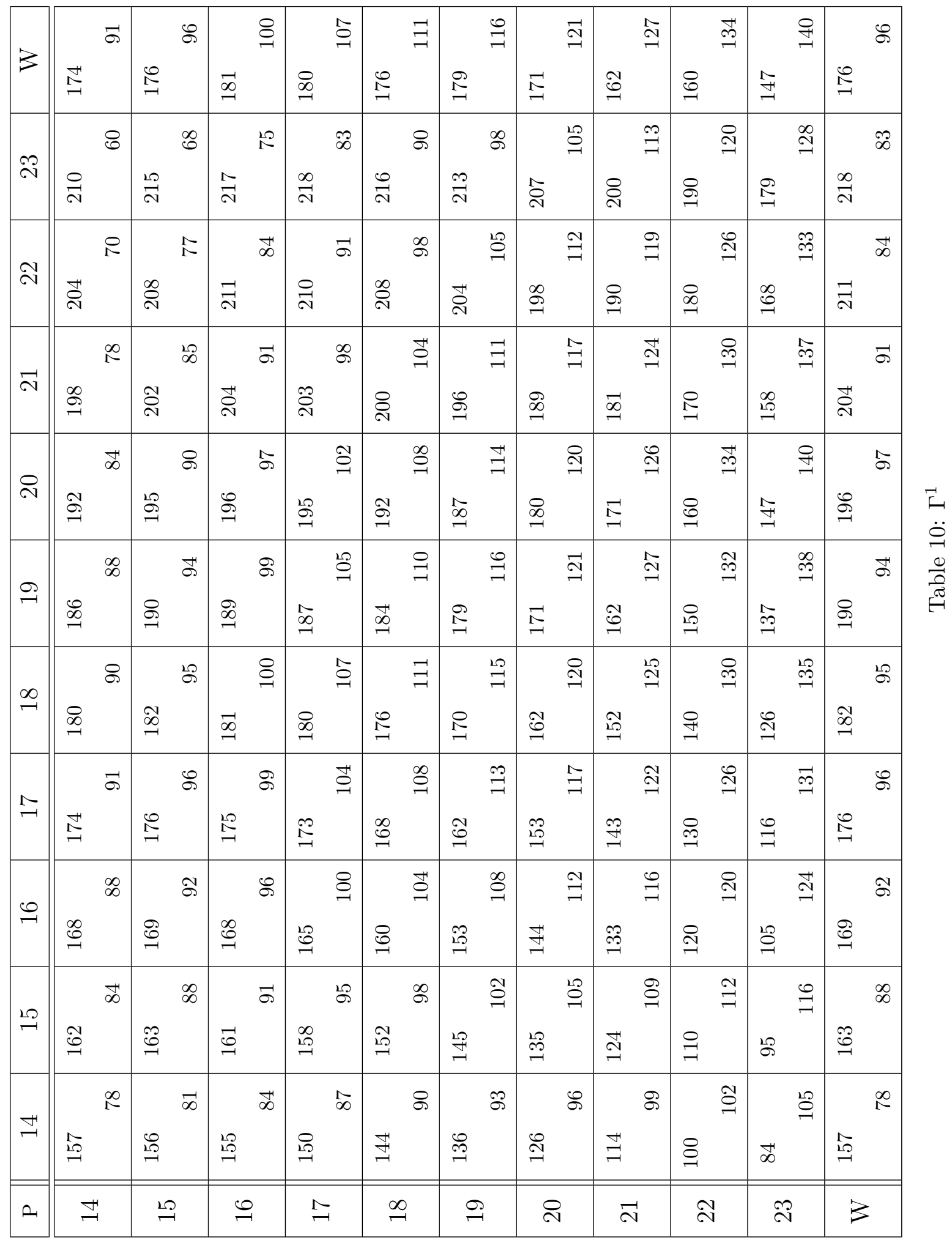




\begin{tabular}{|c|c|c|c|c|c|c|c|c|c|c|c|c|c|}
\hline & $\stackrel{\text { Ij }}{\exists}$ & 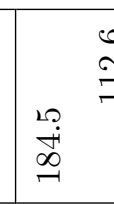 & & & 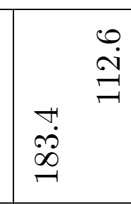 & 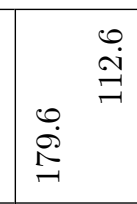 & 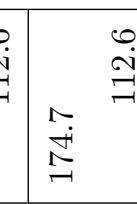 & 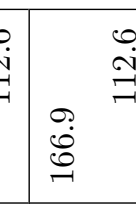 & 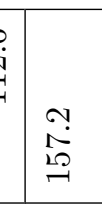 & $\exists$ & 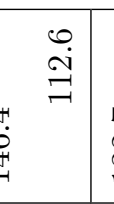 & & 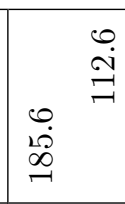 \\
\hline & ๙ & 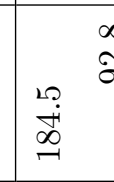 & 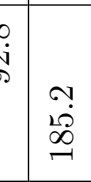 & & 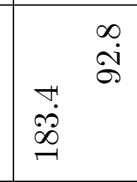 & 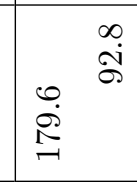 & $\overbrace{\substack{0 \\
0}}$ & 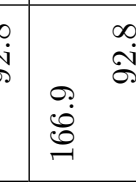 & : & & 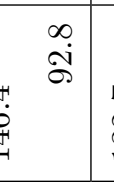 & 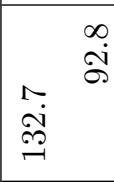 & 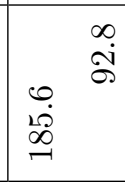 \\
\hline $\mathrm{v}$ & 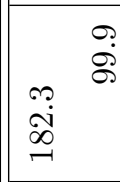 & 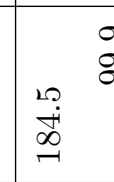 & & & 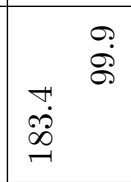 & 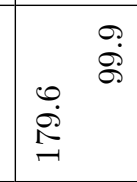 & 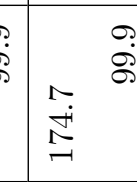 & 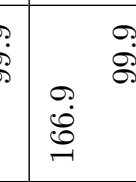 & & $\stackrel{8}{8}$ & 焉 & 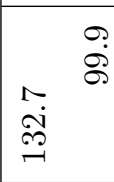 & 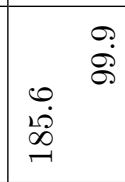 \\
\hline$\vec{v}$ & $\begin{array}{l}\infty \\
\stackrel{\infty}{g} \\
\stackrel{\leftrightarrow}{9}\end{array}$ & 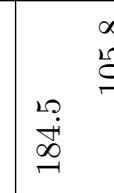 & & $\begin{array}{l}\infty \\
\stackrel{\rho}{g} \\
\stackrel{g}{9}\end{array}$ & 惫 & 惫 & 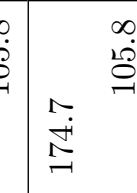 & 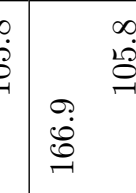 & & 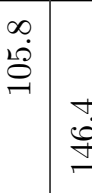 & 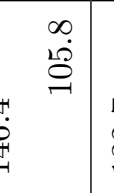 & م) & 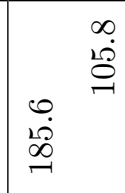 \\
\hline 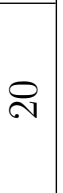 & $\stackrel{\overbrace{}}{\stackrel{\rho}{\exists}}$ & 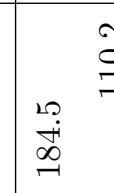 & & & 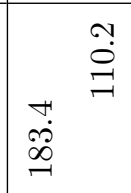 & 总 & 突 & 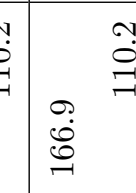 & & $\underset{\Xi}{\tilde{\Xi}}$ & 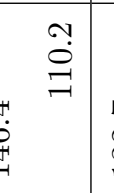 & 疍 & \\
\hline 4 & $\exists$ & 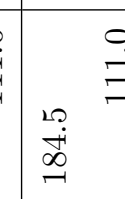 & & & 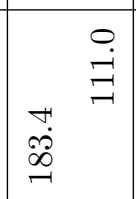 & 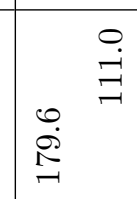 & 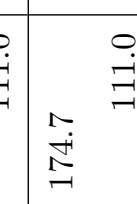 & 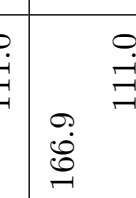 & & & $\stackrel{0}{\stackrel{\exists}{\exists}}$ & 설 & 总 \\
\hline 4 & $\vec{\exists}$ & 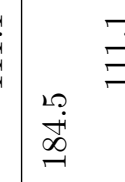 & & $\vec{\Xi}$ & 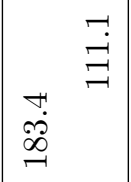 & 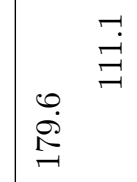 & & 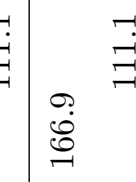 & & $\vec{E}$ & $\vec{\exists}$ & & $\mid$ \\
\hline-1 & 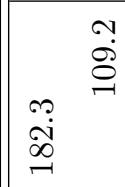 & 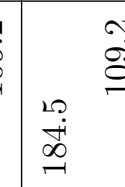 & & $\stackrel{g}{g}$ & 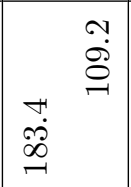 & 罗 & & $\underbrace{g}_{\dot{\theta}}$ & & 苞 & 思 & 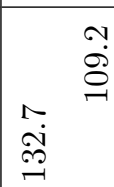 & \\
\hline 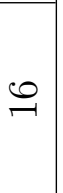 & 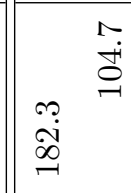 & 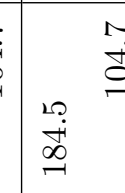 & & 管 & 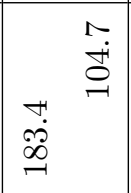 & 总 & 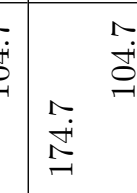 & $\int_{\dot{\theta}}$ & 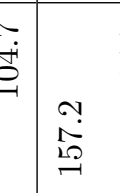 & 突 & 售 & 검 & 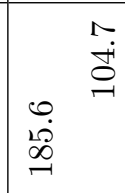 \\
\hline 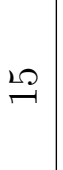 & 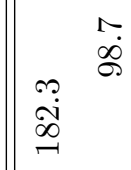 & 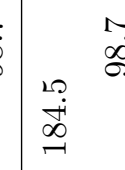 & & 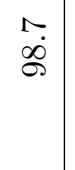 & 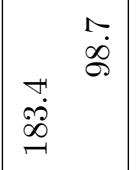 & 泾 & 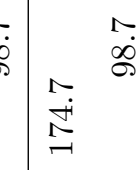 & $\mid$ & 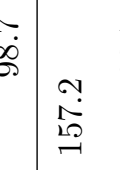 & ğ & 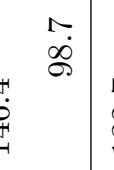 & 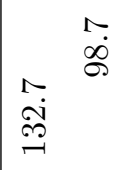 & 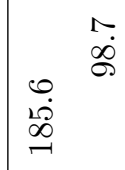 \\
\hline & 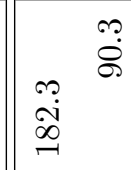 & 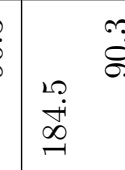 & & & & 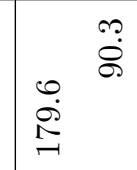 & $\int_{\substack{3\\
}}$ & 8 & 思 & ֶֻ. & 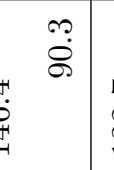 & 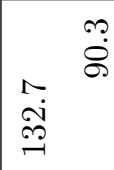 & 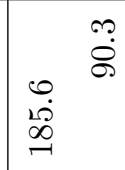 \\
\hline & $\vec{F}$ & $\stackrel{29}{\stackrel{9}{2}}$ & & & $\approx$ & $\stackrel{\infty}{=}$ & $\stackrel{9}{\Rightarrow}$ & จิ & $\vec{~}$ & & & $\approx$ & \\
\hline
\end{tabular}


game, but her payoff function will be $\Pi_{i}^{t}=t \Pi_{i}^{1}\left(p_{i}, p_{j}\right)+(1-t) \Pi_{i}^{0}\left(p_{i}, \rho_{j}\right)$. Let $E^{t}$ be the set of all equilibrium points in $\Gamma^{t}$. By Nash's (1951) existence theorem, we know that $E^{t}$ is non-empty. Let $X=X\left(\Gamma^{t}, z\right)$ be the graph of the correspondence $t \rightarrow E^{t}$ for $0 \leq t \leq 1$. Each point $x$ of $X$ will have the form $x=(t, z)$, where $z$ is an equilibrium point of $\Gamma^{t}$.

Suppose that $X$ contains a path $L$ connecting a point $x^{0}=\left(0, z^{0}\right)$, corresponding to an equilibrium point $z^{0}$ of $\Gamma^{0}$, with a point $x^{1}=\left(1, z^{*}\right)$, corresponding to an equilibrium point $z^{*}$ of the original game $\Gamma^{1}=G$. Then $L$ will be called a feasible path, whereas $x^{0}$ and $x^{1}$ will be called the starting and end points of this path $L$ respectively. $z^{*}$ will be called the outcome selected by $L$. We can now define the linear tracing procedure. It amounts to selecting an outcome $z^{*}$ for the game $G$ by tracing a feasible path from $x^{0}$ to $x^{1}$.

In our auxiliary game $\Gamma^{0}$, we have one equilibrium in pure-strategies, $(W, W)$. Given that equilibrium of $\Gamma^{0}$ is not an equilibrium of $\Gamma^{1}$, we must apply the tracing procedure to ascertain at what point will the two sequential-move equilibria of $\Gamma^{1}$ become equilibria of $\Gamma^{t}$, in order to be able to select the risk-dominant equilibrium. This is done by taking the convex combination of the payoff functions of both games as described above and defining $\Gamma^{t}{ }^{11}$

The point where $(16, W)$ becomes an equilibrium of $\Gamma^{t}$ is $t=0.0741$ since the following equation $181 t+(1-t)(185.2)=176 t+(1-t)(185.6)$ has this t-value as its solution.

The point where $(W, 20)$ becomes an equilibrium of $\Gamma^{t}$ is $t=0.7059$, since the following equation $97 t+(1-t)(110.2)=96 t+(1-t)(112.6)$ has this t-value as solution.

It follows that the equilibrium where the efficient firm leads is selected as the risk-dominant equilibrium of the game, since it becomes an equilibrium of $\Gamma^{t}$ at an earlier moment $(t=0.0741)$ than the equilibrium where the high-cost firm leads $(t=0.7059)$.

\section{Sample Instruction Set — Endogenous Timing Treatment}

Welcome to our experiment. We ask you to remain quiet during the entire experiment and not to communicate with the other people in this room. If you at any point require assistance or have any questions, please raise your hand.

Please read these instructions carefully, since through your decisions and the decisions of other participants, you stand to gain a significant amount of money.

In this experiment, you will be playing the role of a firm, which is paired with another firm in a market for the entire experiment. There are two types of firms, A and B. In each market a firm

\footnotetext{
${ }^{11}$ For presentational reasons we are unable to reproduce the entire game matrix for $\Gamma^{t}$.
} 
A will always be matched with a firm B. You will see your type on the screen, once the experiment begins. Additionally, firm A has a lower cost of producing the good. This means that, for instance, if both firms charge the same price, firm A will make a higher profit than firm B.

In this experiment, your task is to select a price for the good you are producing. If you select a higher price than the other firm, you will still be able to sell some of your goods. However, this means that the other firm will sell more units, the higher your selected price is. Conversely, the higher the price chose by the other firm is, the more units you will sell and therefore the more profits you will make. The currency unit used in this experiment will be called Experimental Currency Unit (ECU).

To help you make your decisions, you will be provided with a table that tells you the profits you will make depending on what prices you and the other firm chose. The first column outlines the prices firm A can choose from and the first row depicts the prices firm B can choose from. In each cell, the profits for both firms resulting from their pricing decisions are shown. Profits for firm A are shown on the upper left-hand corner of each cell, while profits for firm B are shown in the lower right-hand corner of each cell. For instance, if firm A chooses a price of 19 and firm B chooses a price of 17, firm A will make 162 ECUs of profit while firm B will make 113 ECUs of profit.

In each round there will be two periods. You and the other firm will have to make two decisions. Firstly, you will have to decide when to price and then the price you will charge. The decision of when to make the pricing decision has no impact on your profits. However, if you decide to price in the first period, you will not be able to know what the other firm has done until the end of the period. If you choose to make your pricing decision in period 2, you will know whether the other firm has chosen to price in period 1 and the price it chose, or whether the other firm has also chosen to wait.

Once both firms have chosen their prices, the profits for both firms will be calculated and you will be told in a separate screen of what prices both firms have chosen and what were their profits for the round. Additionally, you will be told of your profits up to that point.

We remind you again that you will be interacting with the same firm for the duration of the experiment.

There will be 30 rounds in this experiment. Once the 30 rounds are over, we will calculate the total amount of profit you made in ECUs and convert them into pound sterling, which will be your payment for the experiment. 250 ECU will be worth $£ 1$. 


\begin{tabular}{|c|c|c|c|c|c|c|c|c|c|c|}
\hline$\stackrel{\infty}{\sim}$ & $\stackrel{\circ}{*}^{8}$ & $\stackrel{\infty}{\stackrel{0}{N}}$ & $\overbrace{}^{\frac{1}{2}}$ & ${ }_{\frac{\infty}{N}}^{\infty}$ & $\underbrace{8}$ & $\stackrel{\infty}{\infty}$ & 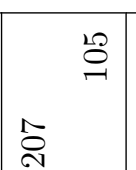 & 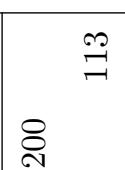 & $\overbrace{\triangle}^{\circ}$ & 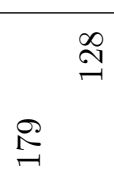 \\
\hline & $R$ & R & $\vec{\infty}$ & $\vec{\sigma}$ & $\infty$ & 哭 & $\Xi$ & $g$ & $\stackrel{g}{9}$ & 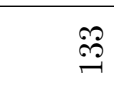 \\
\hline $\mathbb{N}^{2}$ & 荅 & $\stackrel{\infty}{\stackrel{N}{~}}$ & $\overrightarrow{\text { ส }}$ & 고 & $\stackrel{\infty}{\sim}$ & 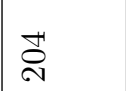 & $\stackrel{\infty}{\stackrel{\Omega}{9}}$ & $\stackrel{8}{\Phi}$ & $\underset{\sim}{\infty}$ & $\stackrel{\leftrightarrow}{\leftrightarrow}$ \\
\hline & $\infty$ & 18 & क & $\stackrel{\infty}{\circ}$ & $\vec{\Delta}$ & $\exists$ & $\exists$ & $\vec{I}$ & $\circ$ & 盗 \\
\hline N & $\stackrel{\infty}{\stackrel{\infty}{\rightarrow}}$ & ลิ & 萮 & 㔛 & ฉ్ & 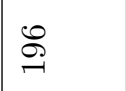 & $\stackrel{\mathscr{D}}{\sim}$ & $\stackrel{\overrightarrow{\underline{D}}}{\sim}$ & $\underset{I}{R}$ & $\stackrel{\mathscr{L}}{\rightarrow}$ \\
\hline & $\vec{\infty}$ & 8 & t. & $\stackrel{\Xi}{g}$ & $\stackrel{\infty}{=}$ & $\vec{\exists}$ & I & I্ & $\overrightarrow{\mathrm{g}}$ & 乎 \\
\hline & $\stackrel{\Xi}{\Xi}$ & $\stackrel{28}{9}$ & $\stackrel{\mathscr{g}}{-}$ & $\stackrel{9}{9}$ & $\underset{\sim}{\stackrel{S}{\sim}}$ & $\stackrel{\leftarrow}{\infty}$ & $\underset{\sim}{\infty}$ & $\vec{E}$ & $\stackrel{\circ}{\circ}$ & 氠 \\
\hline \multirow{2}{*}{ 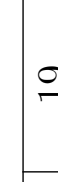 } & $\infty$ & & 8 & 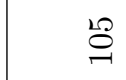 & 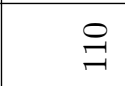 & $\stackrel{\Theta}{\exists}$ & $\vec{\Xi}$ & $\stackrel{\mathfrak{I}}{\mathrm{N}}$ & 㞼 & 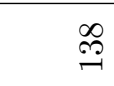 \\
\hline & $\stackrel{\mathscr{D}}{\stackrel{\infty}{\sim}}$ & $\stackrel{\odot}{\stackrel{\Im}{2}}$ & $\stackrel{\mathscr{D}}{\stackrel{\leftrightarrow}{\sim}}$ & 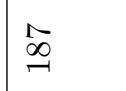 & $\stackrel{.}{\sim}$ & 里 & $\underset{F}{\vec{F}}$ & đ్ֶ & 品 & 鿖 \\
\hline & 8 & 89 & 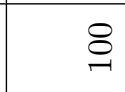 & $\stackrel{\cong}{g}$ & $\exists$ & $\stackrel{20}{\exists}$ & $\stackrel{\Xi}{\Xi}$ & 总 & 吕 & 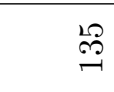 \\
\hline & 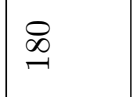 & $\stackrel{\infty}{\infty}$ & $\stackrel{\vec{\Phi}}{\sim}$ & $\underset{\underset{\sim}{\infty}}{\stackrel{\infty}{2}}$ & $\stackrel{\mathscr{I}}{I}$ & 尺 & $\underset{\sigma}{\tilde{\sigma}}$ & 第 & F & I্ \\
\hline & $\vec{\sigma}$ & 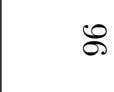 & 8 & 룡 & $\stackrel{\infty}{=}$ & $\stackrel{\Re}{\exists}$ & $\exists$ & ָ̃ & 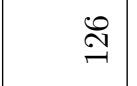 & $\vec{s}$ \\
\hline & $\stackrel{\mathbb{N}}{\mathbb{N}}$ & $\stackrel{0}{1}$ & $\stackrel{18}{9}$ & 象 & $\underset{\sim}{\infty}$ & ઢ્વ & 骂 & 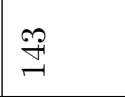 & 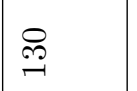 & $\stackrel{\leftrightarrow}{\beth}$ \\
\hline \multirow{2}{*}{$\stackrel{\leftrightarrow}{\hookrightarrow}$} & $\begin{array}{l}\infty \\
\infty\end{array}$ & $\approx$ & $\&$ & $\stackrel{8}{\circ}$ & $\overrightarrow{\stackrel{\Delta}{\sigma}}$ & $\stackrel{\infty}{=}$ & $\Xi$ & $\stackrel{\vartheta}{\exists}$ & $\stackrel{\Xi}{\Xi}$ & 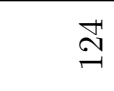 \\
\hline & $\stackrel{\infty}{\stackrel{\leftrightarrow}{*}}$ & $\underset{\mathscr{G}}{\mathscr{8}}$ & $\stackrel{\infty}{\leftrightarrow}$ & 吕 & $\stackrel{\circ}{\circ}$ & 骂 & $\mathbb{E}$ & $\stackrel{\text { g }}{9}$ & 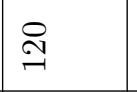 & $\stackrel{g}{g}$ \\
\hline \multirow{2}{*}{$\stackrel{29}{7}$} & $\vec{\infty}$ & $\begin{array}{l}\infty \\
\infty\end{array}$ & क & 8 & $\infty$ & $\stackrel{g}{g}$ & $\stackrel{8}{g}$ & $\stackrel{8}{g}$ & $\exists$ & $\stackrel{\varphi}{\nexists}$ \\
\hline & ஜ্ণ & ஜֶg & $\vec{\Phi}$ & 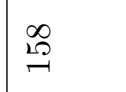 & 总 & 栗 & 骂 & $\vec{I}$ & $\stackrel{\nexists}{\nexists}$ & 88 \\
\hline \multirow{2}{*}{$\mathbb{F}$} & $\stackrel{\infty}{\infty}$ & $\vec{\infty}$ & $\vec{\infty}$ & $\stackrel{\infty}{\infty}$ & 8 & ஜ & $\&$ & 8 & $\stackrel{2}{\circ}$ & $\stackrel{g}{g}$ \\
\hline & 点 & 㽞 & 煦 & 号 & $\mathbb{J}$ & $\stackrel{\leftrightarrow}{\oplus}$ & $\stackrel{\mathscr{I}}{\stackrel{2}{2}}$ & $\exists$ & 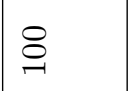 & $\vec{\infty}$ \\
\hline a & $\exists$ & $\stackrel{19}{\rightarrow}$ & $\stackrel{\varphi}{0}$ & 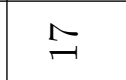 & $\stackrel{\infty}{\sim}$ & 9 & i & $\vec{\lambda}$ & ปิ & 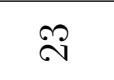 \\
\hline
\end{tabular}

